\title{
Non-compliance with pregnancy prevention recommendations for isotretinoin in Korea between 2019-2020
}

\author{
Eun Jeong Choi, MD ${ }^{1,2}$, Jung Yeol Han, MD, PhD ${ }^{1,3}$ \\ ${ }^{1}$ Korean MotherSafe Counselling Center, Pregnancy \& Breastfeeding Medicines Information Center, Seoul; Department of Obstetrics and Gynaecology, \\ ${ }^{2}$ Hanmaeum Changwon Hospital, Changwon; ${ }^{3}$ Inje University, Ilsan Paik Hospital, Goyang, Korea
}

\section{Objective}

Isotretinoin is commonly prescribed worldwide despite its notorious teratogenicity. A risk management program (RMP) was introduced in Korea to prevent isotretinoin use during pregnancy. Here, we evaluate the compliance of Korean women with the recommendations of the RMP.

\section{Methods}

This prospective cohort study was conducted between April 2019 and June 2020. Thirty-six and 82 patients received the prescription before and after the introduction of RMP, respectively.

\section{Results}

There was a significant difference in the total number of days for which isotretinoin was prescribed before and after the RMP was introduced $(68.8 \pm 100.9$ and $28.0 \pm 26.1$ days, respectively). However, $1.43 \%(120 / 8,394)$ of the total patients contacted by the teratology information services were exposed to isotretinoin on an average.

\section{Conclusion}

The proportion of patients exposed to isotretinoin did not change, and there was no significant change in compliance, with the implementation of the RMP during the study period. Further studies are needed to evaluate the effectiveness of the RMP in the long term.

Keywords: Isotretinoin; Pregnancy; Congenital abnormalities; Risk management; Abortion, induced

\section{Introduction}

Isotretinoin (13-cis-retinoic acid) was approved by the United States Food and Drug Administration (FDA) for cystic and recalcitrant acne in 1982 [1]. Since then, the drug has been widely used around the world, including in the European Union, Australia, and Korea. Isotretinoin is a commonly prescribed teratogenic drug in North America and Korea [2-4]. The risk of congenital malformations associated with isotretinoin exposure in pregnancies is almost $30 \%$. These malformations include brain, cardiovascular, and thymus malformations [5].

Due to its teratogenic risk, the US FDA labelled isotretinoin as a pregnancy category $X$ drug for protecting fetuses. Moreover, many countries, including Korea, have classified isotretinoin as a drug contraindicated during pregnancy. A number of pregnant women exposed to isotretinoin chose to terminate their pregnancy. In Canada, from 1984 to 2002, 90 of 8,609 women of childbearing age who took isotreti-

Received: 2020.08.20. Revised: 2020.10.16. Accepted: 2020.11.08. Corresponding author: Jung Yeol Han, MD, PhD

Department of Obstetrics and Gynaecology Korean MotherSafe Counselling Center, Inje University, Ilsan Paik Hospital, 170

Juhwa-ro, Ilsanseo-gu, Goyang 10380, Korea

E-mail: hanjungyeol055@gmail.com

https://orcid.org/0000-0001-5611-2392

Articles published in Obstet Gynecol Sci are open-access, distributed under the terms of the Creative Commons Attribution Non-Commercial License (http://creativecommons. org/licenses/by-nc/3.0/) which permits unrestricted non-commercial use, distribution, and reproduction in any medium, provided the original work is properly cited.

Copyright $\odot 2021$ Korean Society of Obstetrics and Gynecology 


\section{Obstetrics \& Gynecology Science}

Vol. 64, No. 2, 2021

noin became pregnant, and $76(84 \%)$ chose to terminate their pregnancy [6]. In addition, in the United States, 72\% of women who became pregnant while taking isotretinoin chose therapeutic abortion [7].

Therefore, many risk management programs (RMPs) have been implemented worldwide to prevent isotretinoin use in pregnancy. The aim of the RMP is to protect the patients against the drug's risks, which include birth defects and fetal death. The manufacturer has developed a comprehensive program in consultation with the FDA, to ensure that no woman begins isotretinoin therapy if she is pregnant and no pregnancies should occur while the patient is taking the drug in the USA [8]. The RMPs run by the United States and the European Union include education for both physicians and patients. Such programs include the teratogenic effect of isotretinoin, advocation of the use of at least 2 contraceptive methods while the patient is taking isotretinoin, and the requirement for a pregnancy test before prescribing the drug [9]. The RMPs in the European Union, Australia, New Zealand, and Singapore do not appear to be sufficiently stringent [10]. Contrastingly, the United States has a more active and stricter RMP called iPLEDGE [11]. The iPLEDGE requires the registration of patients prescriber, and pharmacist on a dedicated website, advocates the use of two different types

Table 1. Characteristics of the subjects before and after the implementation of the risk management program

\begin{tabular}{|c|c|c|c|c|}
\hline Characteristics & & Before $(n=36)$ & After $(n=82)$ & $P$-value \\
\hline \multirow[t]{4}{*}{ Age (yr) } & $\leq 24$ & $1(2.8)$ & $6(7.3)$ & 0.161 \\
\hline & $25-29$ & $17(47.2)$ & $31(37.8)$ & \\
\hline & $30-34$ & $16(44.4)$ & $29(35.4)$ & \\
\hline & $\geq 35$ & $2(5.6)$ & $16(19.5)$ & \\
\hline \multirow[t]{2}{*}{ Married } & Married & $29(80.6)$ & $63(76.8)$ & 0.191 \\
\hline & Unmarried & $7(19.4)$ & $19(23.2)$ & \\
\hline \multirow[t]{3}{*}{ Gravidity } & 0 & $1(2.8)$ & $1(1.2)$ & 0.684 \\
\hline & 1 & $25(69.4)$ & $53(64.6)$ & \\
\hline & $>1$ & $10(27.8)$ & $28(34.1)$ & \\
\hline \multirow[t]{2}{*}{ Parity } & 0 & $27(75.0)$ & $63(76.8)$ & 0.830 \\
\hline & $\geq 1$ & $9(25.0)$ & $19(23.2)$ & \\
\hline \multirow[t]{2}{*}{ Artificial abortion } & 0 & $35(97.2)$ & $76(92.7)$ & 0.336 \\
\hline & $\geq 1$ & $1(2.8)$ & $6(7.3)$ & \\
\hline \multirow[t]{2}{*}{ Spontaneous abortion } & 0 & $32(88.9)$ & 77 (93.9) & 0.345 \\
\hline & $\geq 1$ & $4(11.1)$ & $5(6.1)$ & \\
\hline \multirow[t]{2}{*}{ Live birth } & 0 & $27(75.0)$ & $63(76.8)$ & 0.830 \\
\hline & $\geq 1$ & $9(25.0)$ & $19(23.2)$ & \\
\hline \multirow[t]{2}{*}{ Current pregnancy } & No & $1(2.8)$ & $1(1.2)$ & 0.546 \\
\hline & Yes & $35(97.2)$ & $81(98.9)$ & \\
\hline \multirow[t]{2}{*}{ Drinker } & No & $17(47.2)$ & $46(56.1)$ & 0.374 \\
\hline & Yes & $19(52.8)$ & $36(43.9)$ & \\
\hline \multirow[t]{2}{*}{ Cigarette smoker } & No & $33(91.7)$ & $72(87.8)$ & 0.537 \\
\hline & Yes & $3(8.3)$ & $10(12.2)$ & \\
\hline \multirow[t]{2}{*}{ Prescribing physician } & Dermatologist & $34(94.4)$ & 79 (96.3) & 0.640 \\
\hline & Others & $2(5.6)$ & $3(3.7)$ & \\
\hline Daily dose (mg) & & $1.2 \pm 0.5$ & $1.3 \pm 0.6$ & 0.337 \\
\hline Total days of prescription & & $68.8 \pm 100.9$ & $28.0 \pm 26.1$ & 0.031 \\
\hline
\end{tabular}

Values are presented as number (\%) or mean \pm standard deviation. 


\section{Obstetrics \& Gynecology Science}

Eun Jeong Choi, et al. Pregnancy prevention for isotretinoin

of contraception while taking isotretinoin, and pregnancy tests before prescribing the drug.

In Korea, the RMP for isotretinoin was introduced in June 2019. This was after a number of pregnant women who were exposed to isotretinoin in Korea terminated their pregnancy. Between 2010 and 2016, 650 pregnancies were exposed to isotretinoin [4]. Another study showed that $40-50 \%$ of pregnancies were terminated after isotretinoin exposure in the periconceptional period [12]. However, the Korean RMP for isotretinoin is similar to that used in the European Union and is not considered to be stringent enough. Therefore, it is unlikely that the RMP is effective in preventing the use of isotretinoin in Korea during pregnancy. Therefore, in this study, we aimed to evaluate the compliance with pregnancy prevention recommendations according to the RMP for isotretinoin in Korea.

\section{Materials and methods}

\section{Study design and participants}

This study was prospectively conducted between April 2019 and June 2020. A total of 120 phone calls were made by the
Korean MotherSafe Counselling Center for counselling on the teratogenic risk of isotretinoin. This center comprises a network of hospitals located in Seoul and other regional cities and is a teratology information services (TIS) center operating under the support of the Korea Ministry of Health and Welfare since 2010.

The study was approved by the Ethics Review Board of Cheil General Hospital and Women's Health Care Center. This study was conducted according to the principles outlined in the Declaration of Helsinki on research involving human subjects. After verbal consent was obtained, data were collected during telephone counselling by the Korean MotherSafe counselling center. Data collected included demographics, obstetric history, and alcohol and cigarette smoking consumption. In addition, information was collected on the implementation of the RMP recommendations by the Ministry of Food and Drug Safety for preventing use of isotretinoin in pregnancy.

These recommendations include receiving information on teratogenicity by a physician, the patient's confirmation of their knowledge about the drug's teratogenicity with their signature, information on effective contraception, a pregnancy test before therapy, and dispensing the drug within

Table 2. Prescription recommendation changes before and after the introduction of the isotretinoin risk management program

\begin{tabular}{|c|c|c|c|c|}
\hline Recommendations & & Before $(n=36)$ & After $(n=82)$ & $P$-value \\
\hline \multirow[t]{2}{*}{ Information on teratogenicity } & No & $6(16.7)$ & $12(14.6)$ & 0.777 \\
\hline & Yes & $30(83.3)$ & $70(85.4)$ & \\
\hline \multirow[t]{3}{*}{ Medical providers who gave information } & Physician & $28(77.8)$ & $67(81.7)$ & 0.849 \\
\hline & Others & $2(5.6)$ & $3(3.7)$ & \\
\hline & None & $6(16.7)$ & $12(14.6)$ & \\
\hline \multirow[t]{2}{*}{ Written signature on teratogenicity } & No & $32(88.9)$ & $68(82.9)$ & 0.580 \\
\hline & Yes & $4(11.1)$ & $14(17.1)$ & \\
\hline \multirow[t]{2}{*}{ Information on contraception } & No & $22(61.1)$ & $49(59.8)$ & 0.890 \\
\hline & Yes & $14(38.9)$ & $33(40.2)$ & \\
\hline \multirow[t]{2}{*}{ Information on effective contraception period } & No & $31(86.1)$ & $63(76.8)$ & 0.249 \\
\hline & Yes & $5(13.9)$ & $19(23.2)$ & \\
\hline \multirow[t]{2}{*}{ Methods of effective contraception (2 kinds) } & No & $34(94.4)$ & $80(97.6)$ & 0.585 \\
\hline & Yes & $2(5.6)$ & $2(2.4)$ & \\
\hline \multirow[t]{2}{*}{ Pregnancy test before prescription } & No & $36(100.0)$ & $82(98.8)$ & 1.000 \\
\hline & Yes & $0(0.0)$ & $1(1.2)$ & \\
\hline \multirow[t]{2}{*}{ Drug delivery period after prescription } & Within 7 days & $36(100.0)$ & $81(98.8)$ & 1.000 \\
\hline & After 7 days & $0(0.0)$ & $1(1.2)$ & \\
\hline
\end{tabular}

Values are presented as number (\%). 


\section{Obstetrics \& Gynecology Science}

Vol. 64, No. 2, 2021

7 days. Only women who were directly prescribed isotretinoin by a physician were included in the current study, regardless of whether they were pregnant or planned to get pregnant. Women who sourced the drug from a friend or the internet were excluded. Compliance was evaluated by statistical difference in the rate of implementation of prescription recommendation on the drug label before and after the introduction of the RMP.

\section{Statistical analysis}

The $\chi^{2}$ test was used to compare the categorical variables, while the Student's $t$-test was used to compare the continuous variables. A $P$-value of $<0.05$ was considered statistically significant.

\section{Results}

Among the 120 patients screened, two received isotretinoin from a friend. Therefore, a total of 118 patients were eligible for the study. All patients had been prescribed isotretinoin from a physician. Two patients were planning to get preg- nant, and 116 patients were pregnant. Thirty-six patients (30.5\%) and 82 patients (69.5\%) were prescribed isotretinoin before and after the RMP, respectively. The average age of the enrolled patients was 30.0 \pm 4.3 (range, 21-43) years, and the gravidity was $1.5 \pm 0.9$ (range, $0-5$ ). The distribution of patients between the ages of 25-34 years was $91.6 \%$ (33/36) before the RMP and 73.2\% (60/82) after the RMP. The proportion of married patients was $80.6 \%$ (29/36) before the RMP and $76.8 \%$ (63/82) after the RMP. Moreover, there was no significant difference in the obstetric history of the two groups. Furthermore, isotretinoin was prescribed by a dermatologist to $94.4 \%$ (34/36) of the patients before the RMP and $96.3 \%$ (79/82) after the RMP. The daily dose prescribed was $1.2 \pm 0.5 \mathrm{mg}$ before the RMP and $1.3 \pm 0.6 \mathrm{mg}$ after the RMP $(P=0.337)$. Moreover, there was a significant difference in the total number of days for which isotretinoin was prescribed, with $68.8 \pm 100.9$ days before the RMP and $28.0 \pm 26.1$ days after the RMP $(P=0.031$; Table 1$)$. Table 2 shows the compliance of the patients with the implementation of pregnancy prevention recommendations before and after the RMP was introduced. However, there was no significant difference between the recommendations in the period.

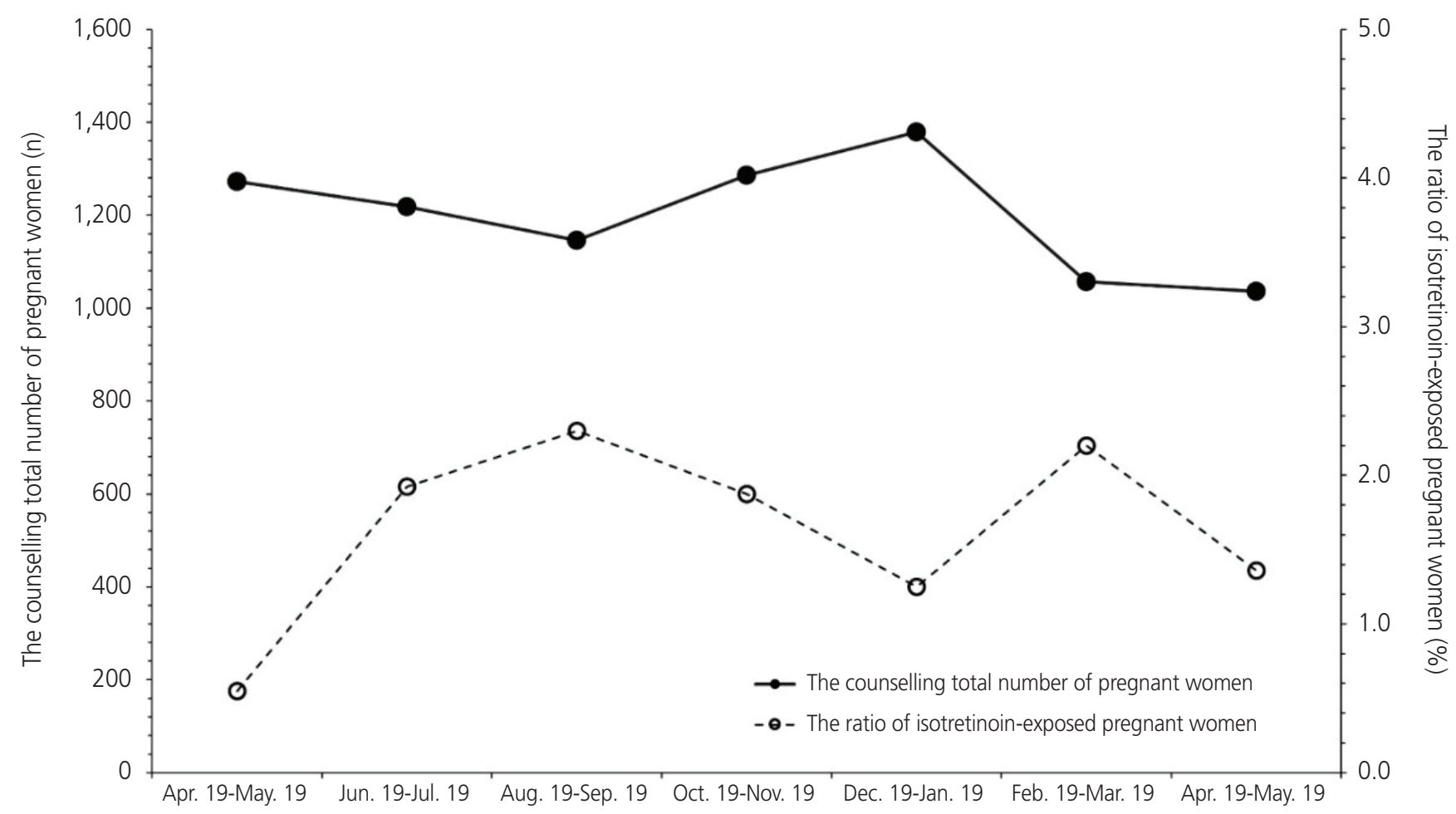

Fig. 1. The proportion of patients exposed to isotretinoin compared to the total patients in the study period. 


\section{Obstetrics \& Gynecology Science}

Eun Jeong Choi, et al. Pregnancy prevention for isotretinoin

This shows that the compliance with the RMP was poor.

Furthermore, $1.43 \%(120 / 8,394)$ of the total patients at the Korean MotherSafe Counselling Center were exposed to isotretinoin on an average; this trend did not change during the study period (Fig. 1). In addition, the average rate of information on the teratogenicity of isotretinoin being provided by a physician, written signature of knowledge as a teratogen, information on effective contraception, pregnancy test before isotretinoin was prescribed, and that the drug was dispensed within 7 days during the study period were $84.7 \%, 15.3 \%, 39.8 \%, 0.8 \%$, and $99.2 \%$, respectively. There were no trends and changes in compliance with the RMP recommendations following the its implementation over 12 months (Fig. 2).

\section{Discussion}

Our study included 118 pregnant women who were exposed to isotretinoin. Compliance with the RMP recommendations was ineffective for preventing isotretinoin use in pregnancy during the study period. Furthermore, 1.43\% $(120 / 8,394)$ of the total patients in the Korean Mother Safe Counselling Center were exposed to isotretinoin; this trend did not change during the study period. In addition, there were no trends or changes in the compliance of the RMP recommendations regarding information on the teratogenicity of isotretinoin, written signature on the knowledge of teratogenicity of isotretinoin, information on effective contraception, pregnancy test before prescription, and the drug being dispensed within seven days before and after the RMP was implemented. The average rate of information on the teratogenicity of isotretinoin being provided by a physician, written signature of knowledge of teratogenicity of isotretinoin, information on effective contraception, pregnancy test before isotretinoin was prescribed, and that the drug was dispensed within seven days during the study period were $84.7 \%, 15.3 \%, 39.8 \%, 0.8 \%$, and $99.2 \%$, respectively. Our data show that there is a big gap between providing information on teratogenicity and information on contraception or a pregnancy test for preventing use in pregnancy, even though the total number of days of prescription after the RMP was implemented is significantly shorter than that before the RMP implementation. Therefore, compliance with

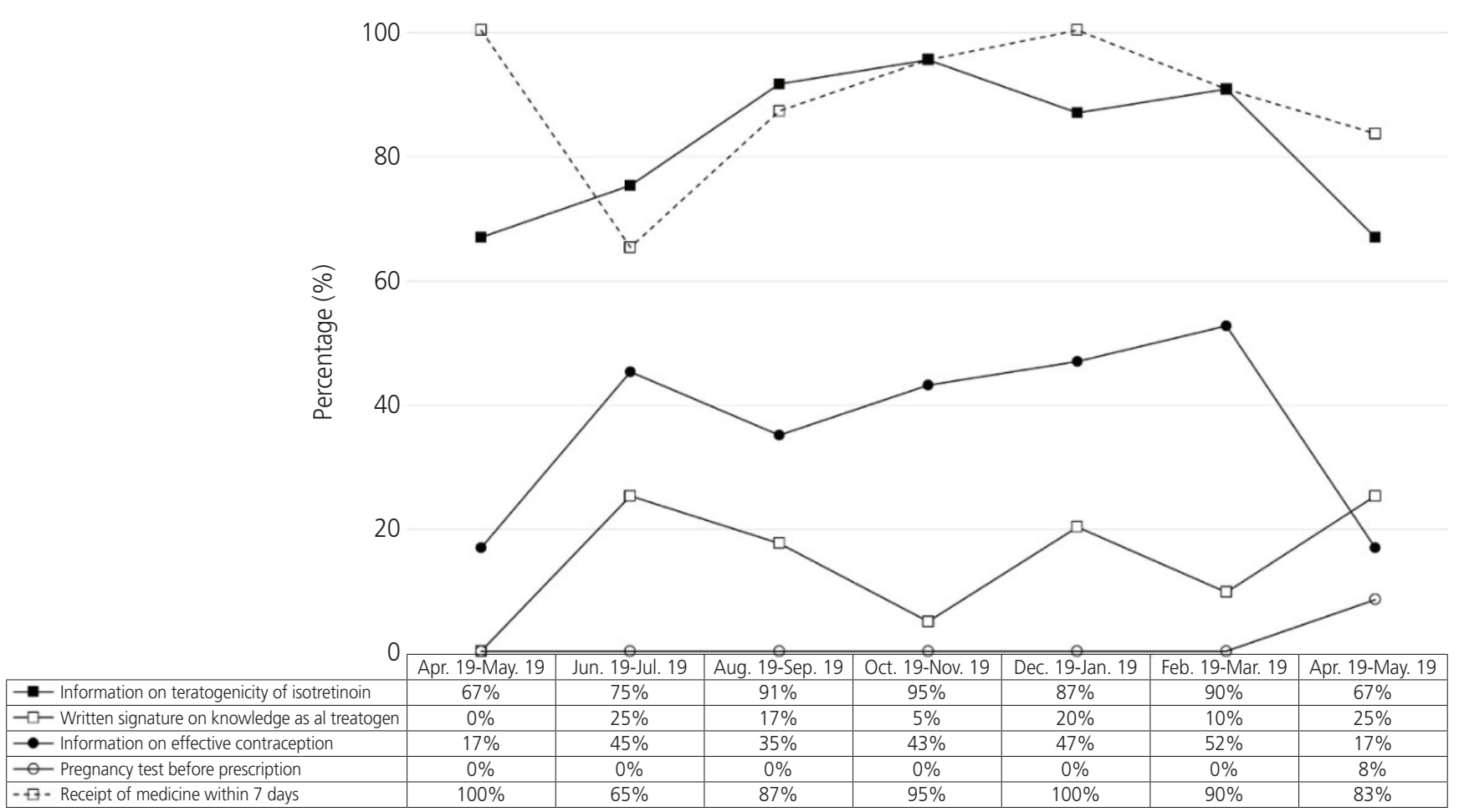

Fig. 2. Trends regarding the knowledge of teratogenicity: written signature on the knowledge of teratogenicity, information of effective contraception, pregnancy test before therapy, and the drug being dispensed within seven days. 


\title{
Obstetrics \& Gynecology Science
}

\author{
Vol. 64, No. 2, 2021
}

the recommendations of the RMP for preventing isotretinoin use in pregnancy in Korea was very poor during the study period. As such, there are several pregnant women exposed to isotretinoin.

Garcia-Bournissen et al. [13] compared the management of the fetal risk of isotretinoin based on TIS in Israel, Italy, and Canada between July 1998 and October 2006. Their study showed that of the 53 pregnant women exposed to isotretinoin, only $41 \%$ reported using a birth control method, just one patient reported using two different forms of contraception, and 53\% terminated their pregnancy. They claimed that fetal exposure to isotretinoin is a global problem. Crijns et al. [14] systematically reviewed the use of isotretinoin in pregnancy and compliance with the pregnancy prevention program (PPP) in Europe. The incidence of pregnancy was 0.2-1.0 per 1,000 women of childbearing age. Between $65 \%$ and $87 \%$ of these pregnancies were terminated. A review of these studies found that the implementation of PPP in Europe had failed.

In addition, Uusküla et al. [15] showed that compliance with pregnancy prevention recommendations for isotretinoin was limited in Estonia between 2012 and 2016. There were 2,792 women aged $15-45$ years, of whom only $15.7 \%$ had full contraceptive coverage. The risk for potential isotretinoin-exposed pregnancy was 3.6 (95\% confidence interval $[\mathrm{Cl}], 2.0-7.0)$ per 1,000 treated women over the 5-year observation period. Contrastingly, the most stringent RMP in the world, iPLEDGE, has been applied since 2006. Shin et al. [16] studied the effect of iPLEDGE relative to the prior RMP, a system to manage accutane-related teratogenicity (SMART), on the risk of isotretinoin fetal exposure in female patients of childbearing potential (FCBP) in a managed care setting between 2004 and 2008. There was a total of 29 fetal exposures and 9,912 isotretinoin treatment courses. After iPLEDGE was implemented, the unadjusted rate of fetal exposure decreased from 3.11 to 2.67 per 1,000 treatment courses $(P=0.69)$. The hazard ratio was $0.76(95 \% \mathrm{Cl}, 0.36-$ 1.61) for fetal exposure to isotretinoin during treatment courses after iPLEDGE implementation compared to SMART [16]. In addition, Pinheiro et al. [17] showed that a small but significant increase in the concomitant use of isotretinoin and contraceptives was observed, and the number of prescriptions for isotretinoin declined after iPLEDGE was implemented.

In 2006, iPLEDGE replaced SMART, including the use of a qualification sticker to remind of the need for a pretherapy negative pregnancy test. The iPLEDGE program for FCBPs includes requirements, such as monthly negative pregnancy test results, patient's completion of online questions about their knowledge of the isotretinoin teratogenic risks, and the registration of doctors, pharmacists, patients, and pharmaceutical companies on a single database. Pharmacists can dispense the medication if the web-based system shows that these requirements are fulfilled. Health practitioners, including general practitioners, physicians, and nurses, can prescribe isotretinoin if they are registered on the iPLEDGE program. However, some studies have suggested that this is not effective in reducing the risk of fetal exposure to isotretinoin. Moreover, these strict regulations have increased the fear of teratogenic risk [10]. In addition, Charrow et al. [18] showed that iPLEDGE might disproportionately contribute to access barriers for non-white patients. In their study, a total of 418 patients were included in the analysis after being ageand sex-matched. It was found that $43.5 \%$ of non-white patients completed their course early compared to $30.1 \%$ of white patients $(P=0.010)$. Despite efforts to reduce barriers to IPLEDGE, patients with lower incomes and those that are non-white are less comfortable with utilizing online patient portals.

According to our study and other published reports, many pregnancies are terminated after exposure to isotretinoin during pregnancy because of insufficient RMPs. Only more stringent RMPs, such as iPLEDGE, are effective. However, the iPLEDGE program has limitations in terms of the prescription of isotretinoin and access to the RMP. This study is the first attempt to study the effectiveness of the RMP and PPP for isotretinoin in East-Southern Asia. It is also the first study to prospectively assess the effectiveness of the RMP before and after its implementation, which will enable quick improvements to be made. This study has several limitations. The subjects were women who were contacted by the TIS, as opposed to a more general sample from the Korean population. Therefore, we do not know the actual number of pregnancies exposed to isotretinoin in Korea. Our sample size was relatively small and imbalanced before and after the RMP implementation. In terms of small sample size, Shin et al. [16] studied the effect of iPLEDGE in a total of 29 fetal exposures. Moreover, smaller samples (36 patients) before the RMP implementation, might have been because of the short foretelling period of the RMP implementation before its 


\section{Obstetrics \& Gynecology Science}

Eun Jeong Choi, et al. Pregnancy prevention for isotretinoin

application by the Ministry of Food and Drug Safety. In spite of the small size and imbalanced study samples, the publication of this study is very important and urgent for increasing the compliance of RMP implementation because there were several pregnancies exposed to isotretinoin during the study period. In addition, there may be a recall bias as some of the pregnant women among the group before the RMP implementation, were interviewed several months after receiving a prescription for isotretinoin, even though a careful interview and data collection procedure was followed with the prospective study.

The present study found no trends and changes in the proportion of patients exposed to isotretinoin and compliance with the RMP recommendations before and after the implementation of the RMP. As the RMP in Korea was not as stringent as it could be, it might not be effective. The RMP should be improved by enhancing the responsibility of the clinicians, pharmacists, patients, and manufacturers under the supervision of the Ministry of Food and Drug Safety to protect pregnant women against the drug's risks, and encouraging information on the use of isotretinoin in pregnancy to be widely disseminated. Further studies are needed to evaluate the long-term effectiveness of the RMP based on a larger sample size.

\section{Acknowledgments}

We thank the counselling team of the Korean Mother Safe Counselling Center for their significant clinical and research contributions.

\section{Conflict of interest}

No potential conflict of interest relevant to this article was reported.

\section{Ethical approval}

This study was approved by the Institutional Review Board of the Cheil General Hospital and Women's Health Care Center, Seoul, Korea (approval number: CGH-IRB-2010-21).

\section{Patient consent}

All participants provided written informed consent.

\section{Funding information}

None.

\section{References}

1. Layton A. The use of isotretinoin in acne. Dermatoendocrinol 2009;1:162-9.

2. Honein MA, Paulozzi LJ, Erickson JD. Continued occurrence of accutane-exposed pregnancies. Teratology 2001;64:142-7.

3. Azoulay L, Oraichi $D$, Bérard A. Patterns and utilization of isotretinoin for acne from 1984 to 2003: is there need for concern? Eur J Clin Pharmacol 2006;62:66774.

4. Kim NR, Yoon SR, Choi JS, Ahn HK, Lee SY, Hong DS, et al. Isotretinoin exposure in pregnant women in Korea. Obstet Gynecol Sci 2018;61:649-54.

5. Lammer EJ, Chen DT, Hoar RM, Agnish ND, Benke PJ, Braun JT, et al. Retinoic acid embryopathy. N Engl J Med 1985;313:837-41.

6. Bérard A, Azoulay L, Koren G, Blais L, Perreault S, Oraichi $D$. Isotretinoin, pregnancies, abortions and birth defects: a population-based perspective. Br J Clin Pharmacol 2007;63:196-205.

7. Mitchell AA, Van Bennekom CM, Louik C. A pregnancyprevention program in women of childbearing age receiving isotretinoin. N Engl J Med 1995;333:101-6.

8. Schwetz BA. From the food and drug administration. JAMA 2002;287:578.

9. Abroms L, Maibach E, Lyon-Daniel K, Feldman SR. What is the best approach to reducing birth defects associated with isotretinoin? PLoS Med 2006;3:e483.

10. Kovitwanichkanont T, Driscoll T. A comparative review of the isotretinoin pregnancy risk management programs across four continents. Int J Dermatol 2018;57:1035-46.

11. iPLEDGE. Committed to pregnancy prevention [internet]. White Oak (MA): iPLEDGE; 2016 [cited 2020 Jul 14]. Available from: https://www.ipledgeprogram.com/ 


\section{Obstetrics \& Gynecology Science}

Vol. 64, No. 2, 2021

iPledgeUl/home.u.

12. Yook JH, Han JY, Choi JS, Ahn HK, Lee SW, Kim MY, et al. Pregnancy outcomes and factors associated with voluntary pregnancy termination in women who had been treated for acne with isotretinoin. Clin Toxicol (Phila) 2012;50:896-901.

13. Garcia-Bournissen F, Tsur L, Goldstein LH, Staroselsky A, Avner $M$, Asrar $F$, et al. Fetal exposure to isotretinoin-an international problem. Reprod Toxicol 2008;25:124-8.

14. Crijns HJ, Straus SM, Gispen-de Wied C, de Jong-van den Berg LT. Compliance with pregnancy prevention programmes of isotretinoin in Europe: a systematic review. Br J Dermatol 2011;164:238-44.

15. Uusküla A, Pisarev H, Kurvits K, Laius O, Laanpere M, Uusküla M. Compliance with pregnancy prevention rec- ommendations for isotretinoin in Estonia in 2012-2016. Drugs Real World Outcomes 2018;5:129-36.

16. Shin J, Cheetham TC, Wong L, Niu F, Kass E, Yoshinaga $M A$, et al. The impact of the iPLEDGE program on isotretinoin fetal exposure in an integrated health care system. J Am Acad Dermatol 2011;65:1117-25.

17. Pinheiro SP, Kang EM, Kim CY, Governale LA, Zhou $\mathrm{EH}$, Hammad TA. Concomitant use of isotretinoin and contraceptives before and after PPLEGE in the United States. Pharmacoepidemiol Drug Saf 2013;22:1251-7.

18. Charrow A, Xia FD, Lu J, Waul M, Joyce C, Mostaghimi A. Differences in isotretinoin start, interruption, and early termination across race and sex in the PLEDGE era. PLoS One 2019;14:e0210445. 